\title{
Age-Dependent Changes in the Function of Mitochondrial Membrane Permeability Transition Pore in Rat Liver Mitochondria
}

\author{
René ENDLICHER $^{1,2}$, Zdeněk DRAHOTA $^{1,3}$, Otto KUČERA $^{1}$, Zuzana ČERVINKOVÁ ${ }^{1}$ \\ ${ }^{1}$ Department of Physiology, Faculty of Medicine in Hradec Králové, Charles University, Hradec \\ Králové, Czech Republic, ${ }^{2}$ Department of Anatomy, Faculty of Medicine in Hradec Králové, \\ Charles University, Hradec Králové, Czech Republic, ${ }^{3}$ Institute of Physiology, Czech Academy of \\ Sciences, Prague, Czech Republic
}

Received May 21, 2021

Accepted September 23, 2021

Epub Ahead of Print October 30, 2021

\begin{abstract}
Summary
Mitochondria play an important role in the cell aging process. Changes in calcium homeostasis and/or increased reactive oxygen species (ROS) production lead to the opening of mitochondrial permeability transition pore (MPTP), depolarization of the inner mitochondrial membrane, and decrease of ATP production. Our work aimed to monitor age-related changes in the $\mathrm{Ca}^{2+}$ ion effect on MPTP and the ability of isolated rat liver mitochondria to accumulate calcium. The mitochondrial calcium retention capacity (CRC) was found to be significantly affected by the age of rats. Measurement of CRC values of the rat liver mitochondria showed two periods when 3 to 17-week old rats were tested. 3-week and 17-week old rats showed lower CRC values than 7-week old animals. Similar changes were observed while testing calcium-induced swelling of rat liver mitochondria. These findings indicate that the mitochondrial energy production system is more resistant to calcium-induced MPTP opening accompanied by the damaging effect of ROS in adult rats than in young and aged animals.
\end{abstract}

\section{Key words}

Rat liver mitochondria - Mitochondrial permeability transition pore $\bullet$ Calcium retention capacity $\bullet$ Calcium-induced swelling

\section{Corresponding author}

Zuzana Červinková, Department of Physiology, Faculty of Medicine in Hradec Králové, Charles University, Šimkova 870, 500 03 Hradec Králové, Czech Republic. E-mail: wolff@lfhk.cuni.cz

\section{Introduction}

The aging of mammalian organisms is extensively studied by many laboratories, but its detailed mechanism was not yet fully elucidated. There is a consensus that aging is a multifactorial process induced by many endogenous and exogenous factors and that mitochondria play a crucial role in it (Kalous and Drahota 1996, Barja 2011, Barja 2014, Cedikova et al. 2016, Son and Lee 2019). It is evident that the growth of mammalian organisms and the functional activity of cell populations require a continuous supply of energy. Therefore, the decline of the mitochondrial energy generation system could be one of the essential indicators characterizing the aging process. Energy producing system localized on the mitochondrial membrane is dependent on the formation of the proton gradient across the inner mitochondrial membrane, and all factors that make the inner membrane permeable decrease the efficiency of energy generation (Brand 2000). Reactive oxygen species (ROS) produced by mitochondria were proposed as the main factor participating in mitochondrial damage during aging (Benzi et al. 1992, Barja et al. 1994, Guerrieri et al. 1996, Lenaz et al. 1997, Davies et al. 2001, Barja 2004, Barja 2014).

The changes in calcium homeostasis also play a critical role in the aging process. In mitochondria, calcium ions regulate MPTP. Increased $\mathrm{Ca}^{2+}$ concentration, in addition to other changes (inorganic phosphate concentration, oxidative stress), causes MPTP opening and may lead to induction of cell death (Brand 2000). Reactive oxygen species decrease the calcium concentration needed for MPTP opening (Drahota et al. 2012a, Endlicher et al.

PHYSIOLOGICAL RESEARCH • ISSN 1802-9973 (online) - an open access article under the CC BY-NC-ND 4.0 license (c) 2021 Institute of Physiology of the Czech Academy of Sciences, Prague, Czech Republic Fax +420 241062 164, e-mail: physres@fgu.cas.cz, www.biomed.cas.cz/physiolres 
2019). The increased formation of ROS and the oxidative damage of mitochondrial membrane lipids and proteins associated with MPTP function and regulation are thus likely to promote MPTP opening during aging and induce cell death (Bonora and Pinton 2014).

\section{Methods}

\section{Chemicals}

All chemicals, unless otherwise stated, were of analytical grade and obtained from Sigma-Aldrich (Germany). Calcium Green-5N was obtained from Thermo Fisher Scientific Inc. (Waltham, MA, USA).

\section{Animals}

Male Wistar rats (50 - $500 \mathrm{~g}) ;(3$ - 17-week old) were obtained from Velaz (Lysá nad Labem, Czech Republic). The rats were housed at $23 \pm 1{ }^{\circ} \mathrm{C}, 55 \pm 10 \%$ humidity, with air exchange $12-14$ times/h and a $12 \mathrm{~h}$ light-dark cycle period. The animals had free access to a standard laboratory diet (ST-1, Velaz, Czech Republic) and tap water. We used rats aged 3, 5, 7, 10, 13, and 17-week for experiments. All animals received care according to the guidelines set by the Animal-Welfare Body of Charles University (Czech Republic) and the EU Directive 2010/63/EU for animal experiments (approval number MSMT- 44579/2014-3). Protocols complied with ARRIVE guidelines. The animals were sacrificed under general anesthesia by exsanguination from the aortic bifurcation. The livers were removed, washed in a cold isolation medium, and cut into small pieces.

\section{Isolation of mitochondria}

All experiments were performed on isolated liver mitochondria. Mitochondria were isolated as described previously (Bustamante et al. 1977). The cut and washed tissue $(3 \mathrm{~g})$ was homogenized at $0{ }^{\circ} \mathrm{C}$ by a Teflon-glass homogenizer in an isolation medium containing $220 \mathrm{mM}$ D-mannitol, $70 \mathrm{mM}$ sucrose, $2 \mathrm{mM}$ HEPES, $0.2 \mathrm{mM}$ EGTA, and $0.5 \mathrm{~g}$ of fatty acid free bovine serum albumin per liter, at a $\mathrm{pH}$ of 7.2 . The $10 \%$ homogenate was centrifuged for $4 \mathrm{~min}$ at $830 \mathrm{~g}$, and the resulting supernatant was centrifuged for $15 \mathrm{~min}$ at $5200 \mathrm{~g}$. The mitochondrial sediment was washed twice (10 min at 11200 and $13000 \mathrm{~g})$ in the isolation medium lacking EGTA and suspended in the same medium to a final volume of $3 \mathrm{ml}$. Isolated mitochondria were stored at $0{ }^{\circ} \mathrm{C}$. All data were measured immediately after isolation.

\section{Determination of mitochondrial proteins}

The mitochondrial protein concentration was determined using the Bradford method with bovine serum albumin as a standard (Bradford 1976).

\section{Measurement of calcium retention capacity}

The mitochondrial retention capacity for calcium (CRC) was evaluated using the membrane-impermeable fluorescent probe Calcium Green-5N on an AMINCOBowman Series 2 spectrofluorometer (Thermo Electron Corporation) using an excitation wavelength of $506 \mathrm{~nm}$ and an emission wavelength of $592 \mathrm{~nm}$. Briefly, $1 \mu \mathrm{M}$ Calcium Green-5N, $10 \mathrm{mM}$ succinate, $0.5 \mu \mathrm{M}$ rotenone, and mitochondria $(0.4 \mathrm{mg}$ protein per $\mathrm{ml})$ were added to $1 \mathrm{ml}$ of swelling medium (125 mM sucrose, $65 \mathrm{mM} \mathrm{KCl}$, $10 \mathrm{mM}$ HEPES, and $\mathrm{pH}$ 7.2). Afterward, calcium chloride $\left(\mathrm{CaCl}_{2}\right)$ was added; its concentration was increased by $1.25 \mu \mathrm{M}$ with every addition. $\mathrm{CaCl}_{2}$ was added repeatedly in the same periods (150 s) at intervals indicated in the text to figures. The probe reversibly binds to calcium ions. Therefore, when calcium is added to the medium, the fluorescence signal increases. When added calcium is accumulated by mitochondria and separated from impermeable fluorophore by the mitochondrial membrane, the fluorescent signal in the medium decreases. After sequential calcium additions, the retention capacity for calcium is reached, the pore opens, accumulated calcium is released from mitochondria to the medium, and the fluorescence signal rises dramatically (Fig.1) (Ichas et al. 1997, Fontaine et al. 1998).

\section{Measurement of mitochondrial swelling}

The swelling of isolated liver mitochondria was measured as described before (Drahota et al. 2012a, Drahota et al. 2012b). Mitochondrial swelling was estimated as a decrease of absorbance at $520 \mathrm{~nm}$ at room temperature on a Shimadzu UV 1601 spectrophotometer in $1 \mathrm{ml}$ of a swelling medium containing $(125 \mathrm{mM}$ sucrose, $65 \mathrm{mM} \mathrm{KCl}, 10 \mathrm{mM}$ HEPES, $\mathrm{pH}$ 7.2) with addition of $10 \mathrm{mM}$ succinate, $0.1 \mathrm{mM} \mathrm{K}$-phosphate, and mitochondria $(0.25 \mathrm{mg}$ protein per $\mathrm{ml})$. After $1 \mathrm{~min}$ of preincubation of mitochondrial suspension $25 \mu \mathrm{M} \mathrm{CaCl}_{2}$ solution was added, and the absorbance changes were detected at $10 \mathrm{~s}$ intervals for further 15 minutes. The maximum swelling rate was calculated after derivation of swelling curves and expressed as $\mathrm{dA}_{520} / 10 \mathrm{~s}$.

\section{Statistical analysis}

The experiments were performed at least five 
times; the representative results are shown. Values are depicted as the means $\pm \mathrm{SD} ; P<0.05$ was set as the statistical significance threshold. Statistical evaluation was performed using GraphPad Prism 6.01 software (La Jolla, CA, USA). The data were first tested for normality by means of the Kolmogorov-Smirnoff test. CRC values did not follow a Gaussian distribution and thus were analyzed by nonparametric Kruskal-Wallis test followed by Dunn's multiple comparisons test. The swelling data with Gaussian distribution were further analyzed by a parametric ANOVA and the Dunnett posttest.

\section{Results}

We started our experiments by determining calcium retention capacity in three age groups of animals: three weeks, seven weeks, and seventeen weeks old. Three weeks old rats are at the end of the suckling period, seven weeks-old are considered as the beginning of sexual maturation, and seventeen weeks are considered as the period of development to senescence when aging processes occur (Ost'adalova and Babicky 2012). Fig. 1 demonstrates that the highest value of CRC was obtained in the group of 7-week old animals. The CRC values were lower in both 3- and 17-week groups. Then we included three more groups: 5, 10, and 13-week old animals. The results we obtained are presented in Fig. 2 and Table 1. When compared with the 7-week group, all other age groups tested have significantly lower CRC values. Based on data presented in Table 1, the CRC values of 7-week old animals are on average $28.8 \pm 6.7 \mathrm{nmol} \mathrm{Ca}^{2+} / \mathrm{mg}$ mitochondrial protein and are used as $100 \%$ values for comparison with other groups. In 3-week old animals, the CRC values decreased to $42.1 \%$, and in 5-week group decreased to $70.6 \%$. In

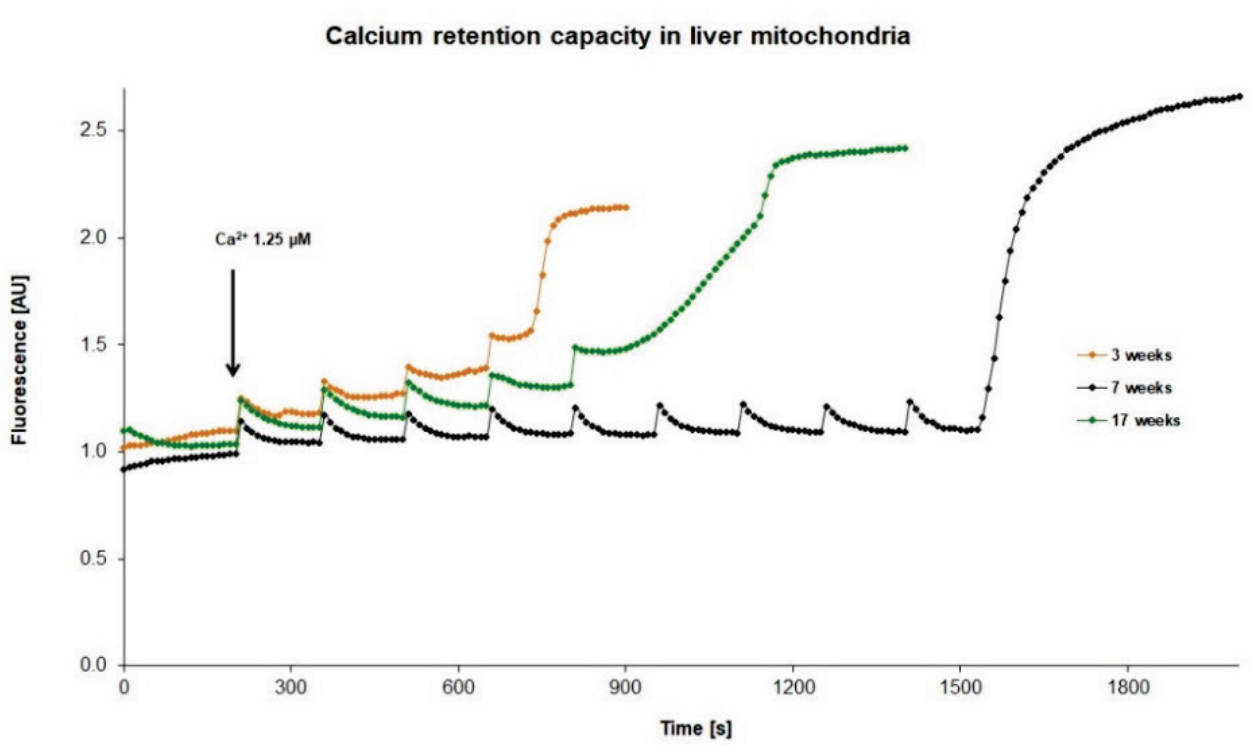

Fig. 1. Representative curves of the mitochondrial CRC of rat liver mitochondria. Mitochondria isolated from 3, 7 and 17-week old rats were titrated by $1.25 \mu \mathrm{M} \mathrm{CaCl}$. The interval between two additions of $\mathrm{CaCl}_{2}$ was $150 \mathrm{~s}$.

Table 1. Determination of calcium retention capacity values (CRC) in isolated rat liver mitochondria.

\begin{tabular}{lccc}
\hline Age of rat & $\begin{array}{c}\text { No. of rats in group/ } \\
\text { No. of mit. samples }\end{array}$ & $\begin{array}{c}\text { CRC - total amount of } \\
\text { accumulated Ca } \\
\text { (nmol/mg prot.) }\end{array}$ & $\begin{array}{c}\text { \% retention } \\
\text { capacity to values } \\
\text { of 7-week }\end{array}$ \\
\hline 3 weeks & $7 / 14$ & $12.11 \pm 3.93 * * *$ & $42.09 \pm 13.67$ \\
5 weeks & $4 / 8$ & $20.31 \pm 4.42 * * *$ & $70.61 \pm 15.36$ \\
7 weeks & $21 / 34$ & $28.77 \pm 6.65$ & $100.00 \pm 23.13$ \\
10 weeks & $9 / 16$ & $20.31 \pm 6.14 * * *$ & $70.61 \pm 20.36$ \\
13 weeks & $8 / 14$ & $18.30 \pm 2.97 * * *$ & $63.62 \pm 10.31$ \\
17 weeks & $8 / 16$ & $16.60 \pm 4.38 * * *$ & $57.71 \pm 15.22$ \\
\hline
\end{tabular}

${ }^{* * *} \mathrm{p}<0.001$ vs 7-week old rats, the values of CRC of rat liver mitochondria isolated from 3 to 17 -week old rats. The values of CRC are expressed in $\mathrm{nmol} \mathrm{Ca}{ }^{2+} / \mathrm{mg}$ protein and in percent compared to 7-week old rats. 

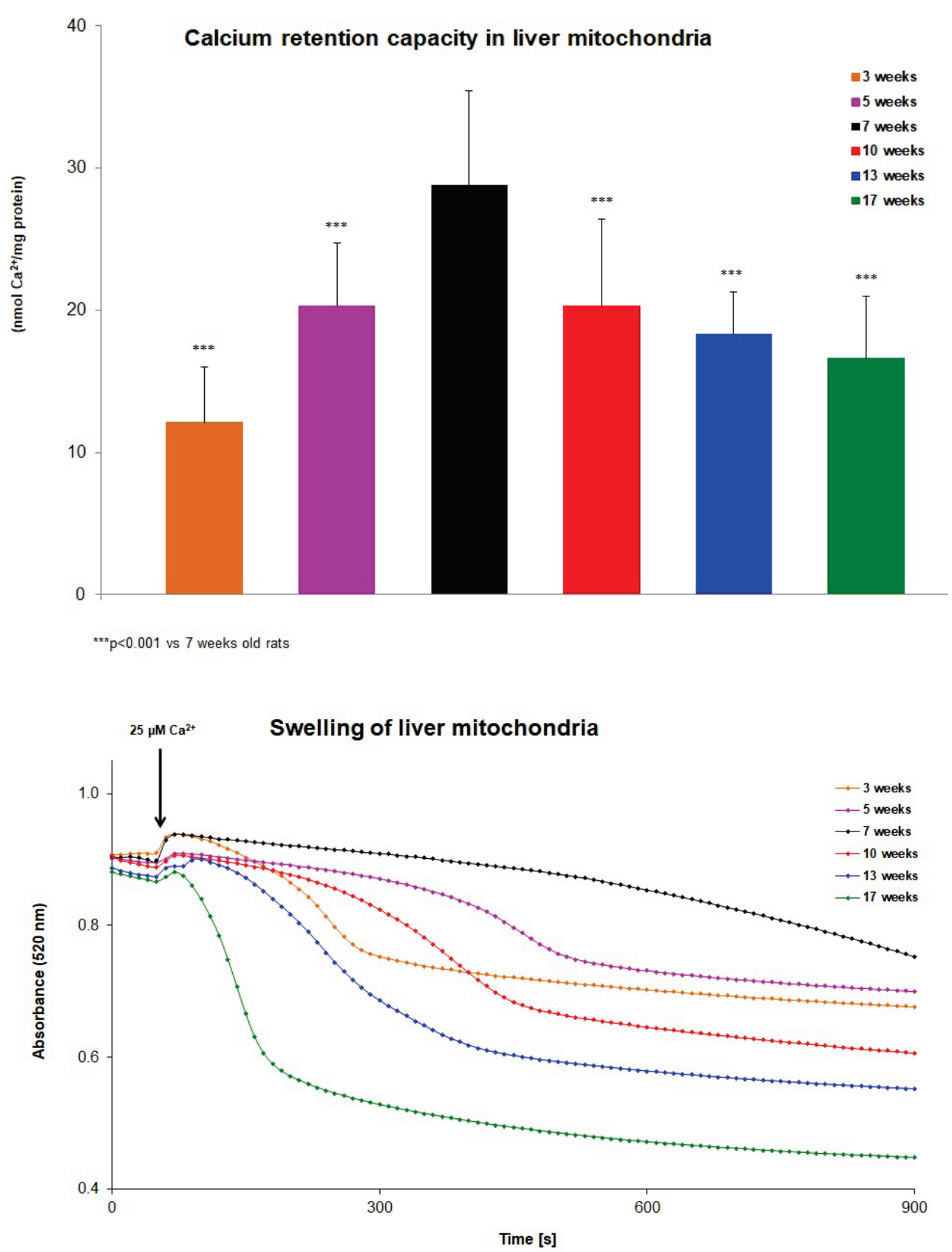

Fig. 2. Statistical evaluation of CRC changes. Mitochondria were isolated from 3 to 17-week old rats. The values of CRC are expressed in nmol $\mathrm{Ca}^{2+} / \mathrm{mg}$ protein. Values of 7-week old animals are used as $100 \%$ values for statistical comparison with other groups. $* * * \mathrm{p}<0.001$ vs 7 -week old rats

Fig. 3. Representative curves of the mitochondrial swelling of rat liver mitochondria. Mitochondria Isolated from 3 to 17 old rats were induced by $25 \mu \mathrm{M}$ $\mathrm{CaCl}_{2}$. older groups of 10-week old animals, the CRC values decreased to $70.6 \%$, in 13 -week old animals, the CRC values decreased to $63.6 \%$, and in 17 -week old animals, to $57.7 \%$ in comparison with 7 -week group.

In further experiments, we used another method to evaluate properties of isolated rat liver mitochondria during aging. We tested calcium-induced swelling of liver mitochondria in animals at the same age (3-17 week) as in previous experiments, where we assessed calcium retention capacity. Data presented in Fig. 3 showed similar age-dependent changes and confirmed findings observed when $\mathrm{CRC}$ values were measured (Fig. 1). The maximum swelling rate values of isolated liver mitochondria from 3 to 17-week old rats are presented in Table 2. The maximum swelling rate values are expressed as changes of $\mathrm{dA}_{520} / 10 \mathrm{~s}$ and in percent compared to 7-week old rats. All tested groups showed an increased swelling rate relative to the control (7-week old animals) group.

\section{Discussion}

Many literature data indicate the age-dependent decline of numerous processes in cell metabolism and in functional activity of all organs. Most of them are related to the decrease of cell energy metabolism. Therefore, all 
Table 2. Determination of maximum swelling rate of isolated rat liver mitochondria induced by addition of $25 \mu \mathrm{M} \mathrm{Ca}^{2+}$.

\begin{tabular}{lccc}
\hline Age of rat & $\begin{array}{c}\text { No. of rats in group/ } \\
\text { No. of mit. samples }\end{array}$ & $\begin{array}{c}\text { maximum swelling } \\
\text { rate (dA520)/10 s }\end{array}$ & $\begin{array}{c}\text { proportion to values } \\
\text { of 7-week (\%) }\end{array}$ \\
\hline 3 weeks & $8 / 8$ & $0.021 \pm 0.015$ & $213.45 \pm 152.94$ \\
5 weeks & $4 / 5$ & $0.013 \pm 0.004$ & $132.44 \pm 43.39$ \\
7 weeks & $7 / 7$ & $0.010 \pm 0.007$ & $100.00 \pm 67.75$ \\
10 weeks & $11 / 11$ & $0.018 \pm 0.013$ & $180.76 \pm 134.64$ \\
13 weeks & $8 / 8$ & $0.015 \pm 0.004$ & $158.01 \pm 42.53$ \\
17 weeks & $8 / 8$ & $0.030 \pm 0.012 * *$ & $310.15 \pm 119.67$ \\
\hline
\end{tabular}

$* * p<0.01$ vs 7 -week old rats, The values of maximum swelling rate of isolated liver mitochondria from 3 to 17 -week old rats. The values of maximum swelling rate are expressed as changes $d A_{520} / 10 \mathrm{~s}$ and in percent compared to 7-week old rats.

these studies aim to understand the detailed mechanism of the aging process, define its starting point, and all factors that may accelerate or slow down this process. As mentioned in the introduction, there is a general agreement that mitochondria play an essential role in generating energy essential for functional activity of all organs and cell repair and recovery and that reactive oxygen species are the main factor damaging this important mitochondrial activity. Previous works described changes in mitochondrial ATP synthase activity (Guerrieri et al. 1994), DNA methylation inducing epigenetic changes of multiple genes coding mitochondrial proteins (Ciccarone et al. 2018), and changes in the degree of fatty acid unsaturation in mitochondrial membranes (Pamplona et al. 1996, Barja 2014). Mitochondrial ROS generation is clearly responsible for all these age-dependent changes (Papa and Skulachev 1997, Barja 2004, Barja 2014). However, overexpression of mitochondrial superoxide dismutase decreased ROS concentration in cells without a corresponding prolongation of life span (Yen et al. 2009).

Therefore, it is necessary to find another way how to protect the mitochondrial energy generating system. Di Lisa and Bernardi (2005) described agedependent changes in the function of MPTP. Its opening induced by calcium ions results in a dissipation of membrane potential across the inner mitochondrial membrane, thus inhibiting ATP generation (Bonora et al. 2015). Therefore, we tested the functional activity of MPTP in isolated mitochondria and found profound changes in CRC during aging. Our data have shown that during the postnatal period, the resistance of mitochondria to calcium effects increases, and adult animals have optimal conditions for energy generation. Then, during further period of ontogenesis, this ability decreased almost to less than $60 \%$ of values detected in adult animals. Our results are in concordance with findings of Mather and Rottenberg (2000). They have shown that the threshold for calcium-induced calcium release was significantly lower in isolated brain and liver mitochondria from aging mice. In addition, it has been repeatedly documented that there are significant differences between different types of mitochondria in their threshold to calcium induced MPTP activation. Mitochondria from mouse liver require a much larger overload of calcium than rat liver.

We confirmed the results obtained by measuring the calcium retention capacity of isolated mitochondria by assessing the rate of calcium-induced swelling in the same age periods. Moreover, our data show the same agedependent changes as obtained by measurement of CRC values. We believe that using these methods could help to find substances able to protect mitochondrial permeability transition pore against harmful effects of ROS and thus help to prolong the life span.

\section{Conflict of Interest}

There is no conflict of interest.

\section{Acknowledgements}

This work was supported by the Charles University Program PROGRES Q40/02.

\section{References}

BARJA G: Free radicals and aging. Trends Neurosci 27: 595-600, 2004. https://doi.org/10.1016/j.tins.2004.07.005 
BARJA G: Longevity and Evolution. New York: Nova Science Publishers, Inc. 2011, pp1-194.

BARJA G: The mitochondrial free radical theory of aging. Prog Mol Biol Transl Sci 127: 1-27, 2014. https://doi.org/10.1016/b978-0-12-394625-6.00001-5

BARJA G, CADENAS S, ROJAS C, LOPEZ-TORRES M, PEREZ-CAMPO R: A decrease of free radical production near critical targets as a cause of maximum longevity in animals. Comp Biochem Physiol Biochem Mol Biol 108: 501-512, 1994. https://doi.org/10.1016/0305-0491(94)90103-1

BENZI G, PASTORIS O, MARZATICO F, VILLA RF, DAGANI F, CURTI D: The mitochondrial electron transfer alteration as a factor involved in the brain aging. Neurobiol Aging 13: 361-368, 1992. https://doi.org/10.1016/0197-4580(92)90109-b

BONORA M, PINTON P: The mitochondrial permeability transition pore and cancer: molecular mechanisms involved in cell death. Front Oncol 4: 302, 2014. https://doi.org/10.3389/fonc.2014.00302

BONORA M, WIECKOWSKI MR, CHINOPOULOS C, KEPP O, KROEMER G, GALLUZZI L, PINTON P: Molecular mechanisms of cell death: central implication of ATP synthase in mitochondrial permeability transition. Oncogene 34: 1475-1486, 2015. https://doi.org/10.1038/onc.2014.462

BRADFORD MM: A rapid and sensitive method for the quantitation of microgram quantities of protein utilizing the principle of protein-dye binding. Anal Biochem 72: 248-254, 1976. https://doi.org/10.1006/abio.1976.9999

BRAND MD: Uncoupling to survive? The role of mitochondrial inefficiency in ageing. Exp Gerontol 35: 811-820, 2000. https://doi.org/10.1016/s0531-5565(00)00135-2

BUSTAMANTE E, SOPER JW, PEDERSEN PL: A high-yield preparative method for isolation of rat liver mitochondria. Anal Biochem 80: 401-408, 1977. https://doi.org/10.1016/0003-2697(77)90661-3

CEDIKOVA M, PITULE P, KRIPNEROVA M, MARKOVA M, KUNCOVA J: Multiple roles of mitochondria in aging processes. Physiol Res 65: S519-S531, 2016. https://doi.org/10.33549/physiolres.933538

CICCARONE F, TAGLIATESTA S, CAIAFA P, ZAMPIERI M: DNA methylation dynamics in aging: how far are we from understanding the mechanisms? Mech Ageing Dev 174: 3-17, 2018. https://doi.org/10.1016/j.mad.2017.12.002

DAVIES SM, POLJAK A, DUNCAN MW, SMYTHE GA, MURPHY MP: Measurements of protein carbonyls, orthoand meta-tyrosine and oxidative phosphorylation complex activity in mitochondria from young and old rats. Free Radic Biol Med 31: 181-190, 2001. https://doi.org/10.1016/s0891-5849(01)00576-7

DI LISA F, BERNARDI P: Mitochondrial function and myocardial aging. A critical analysis of the role of permeability transition. Cardiovasc Res 66: 222-232, 2005. https://doi.org/10.1016/j.cardiores.2005.02.009

DRAHOTA Z, ENDLICHER R, STANKOVA P, RYCHTRMOC D, MILEROVA M, CERVINKOVA Z: Characterization of calcium, phosphate and peroxide interactions in activation of mitochondrial swelling using derivative of the swelling curves. J Bioenerg Biomembr 44: 309-315, 2012a. https://doi.org/10.1007/s10863$\underline{012-9443-2}$

DRAHOTA Z, MILEROVÁ M, ENDLICHER R, RYCHTRMOC D, ČERVINKOVÁ Z, OŠŤÁDAL B: Developmental changes of the sensitivity of cardiac and liver mitochondrial permeability transition pore to calcium load and oxidative stress. Physiol Res 61 Suppl 1: S165-172, 2012b. https://doi.org/10.33549/physiolres.932377

ENDLICHER R, DRAHOTA Z, CERVINKOVA Z: Modification of calcium retention capacity of rat liver mitochondria by phosphate and tert-butyl hydroperoxide. Physiol Res 68: 59-65, 2019. https://doi.org/10.33549/physiolres.933912

FONTAINE E, ERIKSSON O, ICHAS F, BERNARDI P: Regulation of the permeability transition pore in skeletal muscle mitochondria. Modulation By electron flow through the respiratory chain complex i. J Biol Chem 273: 12662-12668, 1998. https://doi.org/10.1074/jbc.273.20.12662

GUERRIERI F, KALOUS M, CAPOZZA G, MUOLO L, DRAHOTA Z, PAPA S: Age dependent changes in mitochondrial FoF1 ATP synthase in regenerating rat-liver. Biochem Mol Biol Int 33: 117-129, 1994.

GUERRIERI F, VENDEMIALE G, TURTURRO N, FRATELLO A, FURIO A, MUOLO L, GRATTAGLIANO I, PAPA S: Alteration of mitochondrial F0F1 ATP synthase during aging. Possible involvement of oxygen free radicals. Ann N Y Acad Sci 786: 62-71, 1996. https://doi.org/10.1111/j.1749-6632.1996.tb39052.x 
ICHAS F, JOUAVILLE LS, MAZAT JP: Mitochondria are excitable organelles capable of generating and conveying electrical and calcium signals. Cell 89: 1145-1153, 1997. https://doi.org/10.1016/s0092-8674(00)80301-3

KALOUS M, DRAHOTA Z: The role of mitochondria in aging. Physiol Res 45: 351-359, 1996.

LENAZ G, BOVINA C, CASTELLUCCIO C, FATO R, FORMIGGINI G, GENOVA ML, MARCHETTI M, PICH MM, PALLOTTI F, PARENTI CASTELLI G, BIAGINI G: Mitochondrial complex I defects in aging. Mol Cell Biochem 174: 329-333, 1997.

MATHER M, ROTTENBERG H. Aging enhaces the activation of the permeability transition pore in mitochondria. Biochem Biophys Res Commun 273: 603-608, 2000. https://doi.org/10.1006/bbrc.2000.2994

OST'ADALOVA I, BABICKY A: Periodization of the early postnatal development in the rat with particular attention to the weaning period. Physiol Res 61: S1-7, 2012. https://doi.org/10.33549/physiolres.932385

PAMPLONA R, PRAT J, CADENAS S, ROJAS C, PEREZ-CAMPO R, LOPEZ TORRES M, BARJA G: Low fatty acid unsaturation protects against lipid peroxidation in liver mitochondria from long-lived species: the pigeon and human case. Mech Ageing Dev 86: 53-66, 1996. https://doi.org/10.1016/0047-6374(95)01673-2

PAPA S, SKULACHEV VP: Reactive oxygen species, mitochondria, apoptosis and aging. Mol Cell Biochem 174: 305-319, 1997.

SON JM, LEE C: Mitochondria: multifaceted regulators of aging. BMB Rep 52: 13-23, 2019. https://doi.org/10.5483/bmbrep.2019.52.1.300

YEN K, PATEL HB, LUBLIN AL, MOBBS CV: SOD isoforms play no role in lifespan in ad lib or dietary restricted conditions, but mutational inactivation of SOD-1 reduces life extension by cold. Mech Ageing Dev 130: 173-178, 2009. https://doi.org/10.1016/j.mad.2008.11.003 